\title{
Awareness of School Learning Environments
}

\author{
Margarida Figueiredo $^{1}$ (D), Henrique Vicente ${ }^{2,3}$ (D) Jorge Ribeiro $^{4}$ (D), \\ and José Neves ${ }^{3(\bowtie)}$ \\ ${ }^{1}$ Departamento de Química, Escola de Ciências e Tecnologia, \\ Centro de Investigação em Educação e Psicologia, \\ Universidade de Évora, Évora, Portugal \\ mtf@uevora.pt \\ 2 Departamento de Química, Escola de Ciências e Tecnologia, \\ Centro de Química de Évora, Universidade de Évora, Évora, Portugal \\ hvicente@uevora.pt \\ ${ }^{3}$ Centro Algoritmi, Universidade do Minho, Braga, Portugal \\ jneves@di.uminho.pt \\ ${ }^{4}$ Escola Superior de Tecnologia e Gestão, ARC4DigiT - Applied Research \\ Center for Digital Transformation, Instituto Politécnico de Viana do Castelo, \\ Viana do Castelo, Portugal \\ jribeiro@estg.ipvc.pt
}

\begin{abstract}
Now, and in the times that follow, student education should focus on developing inclusive skills such as problem-solving and decision-making, where the role of the learning environment plays a crucial part, i.e., it is a process where the screen of the universe of discourse is accomplished in order to consider not only the complex relationships that flow among the objects that populate it, but also its inner structure, co-existing incomplete/unknown or even self-contradictory information or knowledge. As a result, we will focus on the development of an Intelligent Social Machine to assess Learning Environments in high schools, based on factors like School and Disciplinary Climates as well as Parental Involvement. The formal background will be to use Logic Programming to define its architecture based on a Deep Learning-Big Data approach to Knowledge Representation and Reasoning, complemented by an Evolutionary approach to Computing grounded on Virtual Intellects.
\end{abstract}

Keywords: Artificial Intelligence - Intelligent Learning Environments Logic Programming $\cdot$ Knowledge Representation and Reasoning Evolutionary Computation · Intelligent Social Machine 